\title{
A CONTRIBUIÇAO DOS PORTAIS BRASILEIROS PARA A SOCIEDADE INFORMACIONAL NO PROCESSO DE INFORMAÇAO AMBIENTAL SOBRE A ÁGUA
}

\author{
LA CONTRIBUCIÓN DE LOS PORTALES BRASILEÑOS PARA LA SOCIEDAD \\ DE INFORMACIÓN EN EL PROCESO DE INFORMACIÓN AMBIENTAL SOBRE \\ EL AGUA
}

\author{
${ }^{1}$ Micheli Capuano Irigaray \\ ${ }^{2}$ Francielle Benini Agne Tybusch
}

\begin{abstract}
RESUMO
O presente artigo analisa o direito de acesso à informação ambiental na sociedade informacional, especialmente as informações referentes à água em portais brasileiros. A problemática de pesquisa consiste em verificar a existência de portais brasileiros que disponibilizam informações sobre a água aos cidadãos. Utilizou-se o método dedutivo e como procedimento, a análise bibliográfica e de sites. Assim, constatou-se a emergência da efetivação do direito de acesso as informações referentes à governança e gestão dos recursos hídricos, além da necessidade de abertura de novos canais de comunicação e de participação entre o cidadão e a gestão pública pelo princípio da transparência
\end{abstract}

Palavras-chave: Portais brasileiros, Sociedade informacional, Informação ambiental, Água

\section{RESUMEN}

En este artículo se analiza el derecho de acceso a la información ambiental en la sociedad de la información, especialmente la información relacionada con el agua en los portales brasileños. El problema de investigación es verificar la existencia de portales brasileños que proporcionan información sobre el agua a los ciudadanos. Se utilizó el método deductivo y el procedimiento de la revisión de la literatura y el sitio. Por lo tanto, no fue la aparición de la realización del derecho a acceder a la información con respecto a la gobernabilidad y la gestión de los recursos hídricos.

Palabras-claves: Portales brasileños, Sociedad informacional, Información ambiental, Agua

\footnotetext{
${ }^{1}$ Mestranda em Direitos Emergentes na Sociedade Global pela Universidade Federal de Santa Maria - UFSM, Rio Grande do Sul (Brasil). Professora de Direito e Legislação pela E.E. Nossa Senhora do Patrocinio - ESCOLA, (Brasil). E-mail: capgaray@ brturbo.com.br

${ }^{2}$ Doutoranda em Direito pela Universidade do Vale do Rio dos Sinos - UNISINOS, Rio Grande do Sul (Brasil) Professora em Direito pela Grécia Cursos Preparatórios - GRÉCIA, Rio Grande do Sul (Brasil)

E-mail: fra_agne@hotmail.com
} 


\section{INTRODUÇÃO}

As crises ambientais globais, regionais e locais verificadas nas últimas décadas estão levando as nações a buscarem modelos mais efetivos de desenvolvimento que reduzam a utilização de recursos naturais, a poluição e a degradação ambiental. A preocupação com a crise da água no Brasil também vem exigindo do poder público novos modelos para estruturação, gerenciamento e utilização dos recursos hídricos, associados à revolução tecnológica da informação e comunicação.

Nesse sentido, a preocupação com a água, a partir da concepção de um direito fundamental e como do direito ao acesso as informações referentes à sua gestão, estão diretamente relacionados aos interesses sociais, de crescimento econômico, tecnológico e científico com a preservação do direito fundamental à vida. Assim, este trabalho tem como objetivo analisar o direito de acesso à informação ambiental na sociedade informacional, especialmente as informações referentes à água em portais brasileiros.

A relevância dessa informação para o exercício de uma cidadania ambiental, de uma efetiva participação na vida política confere ao cidadão um papel ativo na tomada de decisão em um contexto político e social. O direito de informação destaca-se como direito humano e fundamental, no qual a participação democrática depende da habitualidade dos cidadãos de acesso à informação. Desta maneira, a problemática de pesquisa consiste em verificar a existência de portais brasileiros que disponibilizam informações sobre a água aos cidadãos.

A importância da temática se dá, pois, nas últimas décadas, há o reconhecimento cada vez maior de que o acesso à informação sobre o meio ambiente é chave para a participação efetiva da população na governança ambiental e para o desenvolvimento sustentável. A informação passa a ter uma relevância fundamental na sociedade informacional representando domínio e poder, com efeitos crescentes na economia, na política e na relação do homem com a natureza.

Nesse contexto, a informação caracteriza-se como a base das relações humanas e sociais, em vários graus de complexidade, bem como em torno da estrutura científica, das organizações e da política, sendo assim, o conceito de informação ${ }^{1}$ implica em um estado de consciência sobre fatos e dados.

Salientando-se ainda, que a informação possa ser produzida por vários sistemas, em um processo de troca entre o sistema e o seu meio, mediante o desenvolvimento e utilização

\footnotetext{
${ }^{1}$ A informação que será abordada ao longo deste trabalho, será a informação ambiental sustentável. Pois atenta para as questões sociais, econômicas, políticas, jurídicas e culturais (AGNE TYBUSCH, 2016, p. 12).
} 
de novas tecnologias da informação e das telecomunicações. Dessa forma, é direito do cidadão ter acesso adequado a informações relativas ao meio ambiente, especialmente quanto à água e sua gestão, bem como da oportunidade de participação dos processos decisórios. E o poder público no seu dever de prestá-las de forma clara e transparente, em níveis suficientes a conscientização e participação popular.

É sobre essa temática que versa o presente trabalho, que possui como metodologia o método de abordagem dedutivo, como procedimento, a análise de portais, bibliográfica e documental, e como técnica, fichamentos e resumos estendidos. Foram realizadas pesquisas em sites de busca e sites do governo Brasileiro, sendo que os que mais se destacaram em grau de informações sobre a água, na atualidade, foram: Sabesp - Sistema Cantareira; IDEC - Tö sem água; ANA - Hidro Web; Sistema de Informações Hidrológicas; ANA Conjuntura dos Recursos Hídricos; Estado do Rio Grande do Sul- Cartilha do Usuário da Água; Instituto Trata Brasil; Embrapa - Água para Agricultura; Ministério do Meio Ambiente - Água doce de qualidade; Portal Brasil - Vigiagua - Programa Nacional de qualidade da água para consumo.

Essa reflexão abordará no primeiro capítulo o direito à informação na sociedade informacional; no segundo, o direito de acesso à informação da água no Brasil; e, no terceiro, os portais brasileiros que disponibilizam informações ambientais sobre a água.

\section{O DIREITO À INFORMAÇÃO NA SOCIEDADE INFORMACIONAL}

A informação como direito na sociedade informacional, vem se destacando como instrumento na busca por liberdades, por garantias de direitos fundamentais, conforme observa Giddens (1991.p. 11-13), no final do século XX no limiar de uma nova era, na qual as ciências sociais devem responder para além da própria modernidade, emerge um novo tipo social, denominado como "sociedade de informação" ou "sociedade de consumo", com contornos de uma nova ordem pós-moderna.

O avanço tecnológico e as inovações científicas caracterizam essa nova modernidade, uma sociedade complexa e de risco, que produz demandas diferenciadas para o direito, refletindo-se em preocupações em todas as suas dimensões, devido ao crescimento acelerado do consumo, alto índice populacional, aliados ao grande desafio de sustentabilidade ambiental.

Castells (1999, p. 64-65) utiliza a expressão "sociedade informacional” para definir a nova vida em sociedade, marcada por um contexto revolucionário pelo uso das tecnologias 
de informação e comunicação (TIC) e pelo fluxo rápido de informação, indicando assim, um atributo de uma forma específica de organização social em que a geração, o processamento e a transmissão da informação tornam-se as fontes fundamentais de produtividade e poder devido às novas condições tecnológicas surgidas nesse período histórico.

O direito à informação na sociedade informacional ganhou grande relevância a partir da Revolução Industrial no século XIX, a economia começou a se descolar da política e a soterrar a ética, nas palavras de Boff (2014, p. 26-27) surgiu uma economia de mercado na qual todo sistema econômico fosse dirigido e controlado apenas pelo mercado, livre de qualquer controle ou de um imperativo ético. Dessa forma colocando a sociedade numa situação de um caminho de mercantilizar tudo.

Essa análise da sociedade informacional, na era global, repercute em realidades locais e globais em transformação, que necessitam do Estado, como elo norteador, capaz de informar a sociedade quando aos riscos eminentes advindos do crescimento econômico regido pelo poder hegemônico, em que tudo é alienável, em que os recursos naturais viraram mercadorias. A informação surge nesse cenário, como elemento fundamental para possibilitar uma nova forma de comportamento social, de conscientização quanto à utilização dos recursos naturais na sociedade de consumo.

A sociedade informacional frente à segurança e perigo, confiança e risco, destacados por Giddens (1991, p. 31) vive um desencaixe, de transição do mundo tradicional ao mundo moderno em termos de conceitos diferenciação ou especialização funcional, mudança de sistemas de pequena escala para civilizações agrárias, para sociedades modernas, como um processo de progressiva diferenciação interna. Essa sociedade detentora da técnica e da informação tende a estar vinculada a uma perspectiva evolucionária, não dando atenção ao problema da limitação na análise dos sistemas societais.

O elemento informação surge como norteador no processo de tomada de decisões, possibilitando alternativas para análise de riscos, para o conhecimento dos fenômenos naturais e sociais, na busca de um desenvolvimento sustentável.

O Estado se vê demandado a disciplinar a manutenção dos recursos naturais, a fornecer à sociedade, elementos de informações suficientes para tomada de decisões, dando ao indivíduo a alternativa de calcular os riscos. Sendo que sem informação adequada e transparente, a sociedade se vê as cegas, sem o poder de escolha, sem ferramentas para tomada de decisão. 
Segundo Gonçalves (2003, p. 278-279) a questão jurídica se torna um intenso debate, ao estabelecer a norma legal em aberto conflito, de interesses e tendo a luta política como protagonista, ressaltando ainda, necessidade da democracia, para debater a questão das territorialidades, das relações sociais e com a natureza num espaço - tempo determinado que, cada vez mais, implica a imbricação de diversas escalas.

Nesse contexto, o Poder Judiciário tem sido o mais demandado, pela inoperância dos órgãos públicos, quanto à garantia efetiva do direito de acesso a informação e dos direitos fundamentais, direitos emergentes de uma sociedade informacional, de embate entre seus atores, nas novas formas de interação social, de garantias individuais e coletivas, pela regulação das informações públicas pela relevância e impacto que as mesmas têm no contexto social, econômico e político.

Gonçalves (2003) descreve o desencaixe entre os lugares que detêm a tecnologia e os lugares que detêm a diversidade biológica e cultural atualiza o histórico e desigual padrão de poder moderno-colonial que está na base das tensões de territorialidades que se aguçam no período de globalização neoliberal. $\mathrm{O}$ direito da informação relacionado às liberdades e direitos emergentes e as formas e conteúdos da regulação pública da informação e da comunicação, são analisado por Gonçalves (2003, p. 10) enquanto interesses protegidos e o modo de compatibilizá-los com o contraditório e com os conflitos. Direitos emergentes na sociedade da informação que prolongam ou subvertem direitos codificados no quadro de paradigmas jurídico-políticos anteriores, bem como do paradigma desigual liberal/democrático.

A informação como mecanismo de redução de desigualdades, auxilia a sociedade nos processos de participação e tomada de decisões, assim como proporciona a possiblidade de proteção de riscos ambientais, especialmente em relação à água, quanto a sua disponibilidade, quantidade e qualidade, formas de utilização e previsões de racionamento, tem sido uma das grandes preocupações da população brasileira.

Nesse sentido, a internet é um importante meio de realizar igualdade social e participação democrática, observada por Gonçalves (2003, p. 10-13) como uma potencialidade para emancipação individual, e nas palavras de Habermas potencializar o princípio da discussão, de democracia discursiva e de uma lógica de cidadania e participação democrática, mas reproduzindo antes a tendência da lógica do mercado já presente na era informática.

Na era informática, a formação dos direitos e da regulação é acompanhada, por dois tipos de tensões: 
[...] a tensão entre os direitos de natureza privada sobre a informação, máxime o direito de propriedade, e a liberdade de informação; e a tensão entre as proibições, outras restrições ou condições de acesso à informação (ou a determinadas categorias de informação) e a liberdade de informação (GONÇALVES, 2003, p. 13).

Somente com base em informações relevantes os indivíduos são capazes de formular uma leitura adequada da realidade e influenciar positivamente nos processos decisórios em diferentes esferas da sociedade, conforme Luño (2012, p. 22) a informação, apresenta-se como ferramenta indispensável de controle democrático sobre instituições estatais, através de monitoramento e da participação, razão pela qual o direito à informação está intimamente ligado ao conceito de democracia participativa e respeito aos direitos fundamentais. Por isso, a faculdade de comunicação e o acesso à informação passam a ser formas irrenunciáveis de liberdade, pelo atual desenvolvimento tecnológico.

O direito de acesso à informação, enquanto dimensão do Direito à informação pressupõe a abertura dos governos e das instituições públicas e a atuação transparente, o que os conduz a um cenário desafiador, exigindo-lhes novas competências técnicas, organizacionais e estruturais. Nessa perspectiva, a utilização das tecnologias de informação e de comunicação se apresentam como formas de interação política e social entre a Administração Pública e os cidadãos.

De acordo com as argumentações dos autores citados, quanto à relevância do direito a informação na sociedade informacional, observa-se a indispensabilidade do acesso à informação para efetiva participação dos cidadãos nos processos de decisão e de formação de consciência na preservação ambiental, especialmente quanto à gestão dos recursos hídricos.

\section{O DIREITO DE ACESSO À INFORMAÇÃO DA ÁGUA NO BRASIL}

No Brasil o acesso à informação de qualidade atua na proteção e no desenvolvimento de toda a coletividade, o direito fundamental à informação permite que o cidadão exerça algum controle sobre a ação da Administração, tanto no contexto da governabilidade como o da gestão ambiental. Os sistemas de informação, de indicadores e índices ambientais vêm ganhando importância nos processos de tomada de decisão e passam a ser tratados como tema prioritário nas agendas ambientais e na formulação e execução de políticas públicas.

O acesso à informação está disposto na Constituição Federal Brasileira de 1988, no art. $5^{\circ}$, XXXIII (BRASIL, 2015): 
[...] todos têm direito a receber dos órgãos públicos informações de seu interesse particular, ou de interesse coletivo ou geral, que serão prestadas no prazo da lei, sob pena de responsabilidade, ressalvadas aquelas cujo sigilo seja imprescindível à segurança da sociedade e do Estado;

Um dos principais fundamentos da transparência dos atos governamentais é a garantia de acesso dos cidadãos às informações coletadas, produzidas e armazenadas pelas diversas agências estatais, na relação com o poder público, o acesso livre e transparente protege o cidadão, sendo também condição para sua participação nos processos políticos e na gestão da coisa pública, de democracia efetiva.

Dessa forma, a Constituição da República Federativa do Brasil dispõe que todos têm direito a receber informações independente de seu estado civil, de sua nacionalidade, de seu gênero, ter comunicação, receber as informações dos órgãos públicos, e que estes sejam ativos no dever de informar. Observa Machado (2006, p. 57), que a Administração Pública não pode ficar passiva diante do dever de informar, reconhecido o "interesse coletivo e geral" juntamente com o "interesse particular" dos que recebem ou quiserem receber a informação, sendo assim, o direito à informação não só para assuntos de interesse particular, mas também de interesse coletivo ou geral de controle popular.

A obrigação de publicidade da administração pública elencada no artigo 37 da Constituição Federal (BRASIL, 2015) prevê que:

A administração pública direta ou indireta de qualquer dos Poderes da União, dos Estados, do Distrito Federal e dos Municípios obedecerá aos princípios de legalidade, impessoalidade, moralidade, publicidade e eficiência.

Assim o princípio da publicidade, não se destina somente à elaboração técnica dos atos administrativos propriamente ditos, mas também para nortear o poder público no seu dever de agir com a maior transparência possível, deixando a Administração Pública visível em todos os momentos.

A Lei $n^{\circ} 12.527$ que dispõe sobre os procedimentos a serem observados pela União, Estados, Distrito Federal e Municípios, com o fim de garantir o acesso a informações, representa um novo paradigma de uma cultura de sigilo e segredo em relação a informações públicas para uma cultura de transparência e controle social na Administração. Suas diretrizes, de acordo com o artigo $4^{\circ}$, dispõem sobre a observância da publicidade dos 
atos da administração pública, como preceito geral e do sigilo como exceção das informações de interesse público, independente de solicitações. ${ }^{2}$

Assim, a utilização das TIC visa promover amplo acesso às informações públicas, para a efetivação do princípio da transparência em favor do exercício do controle social pela população, imprescindíveis na proteção do meio ambiente e da sustentabilidade. No artigo $7^{\circ}$, do mesmo diploma legal, a previsão do direito de acesso à informação compreende a possibilidade de o cidadão obter orientações sobre os procedimentos para a consecução de acesso, bem como sobre o local onde poderá ser encontrada ou obtida a informação almejada.

Estes dispositivos evidenciam que o Brasil visa promover amplo acesso às informações públicas, utilizando-se do potencial das TIC, para promoção a transparência em favor do exercício do controle social pela população. Quanto às informações referentes à água, a Política Nacional do Meio Ambiente, instituída pela Lei $n^{\circ}$ 6.938/1981 definiu dentre seus instrumentos de implementação de acesso à informação, o Sistema Nacional do Meio Ambiente - Sisnama,${ }^{3}$ e o Sistema Nacional de Informação sobre Meio Ambiente - Sinima, ${ }^{4}$ atualmente sob a responsabilidade do Ministério do Meio Ambiente. O Sinima, objetiva dar suporte ao planejamento e monitoramento de questões ambientais relevantes para o país, além de subsidiar a tomada de decisões e de fortalecer o intercâmbio e a cooperação institucional para uma gestão ambiental integrada (MMA, 2015).

Pela relevância do acesso a informações sobre meio ambiente para a governança ambiental e participação da sociedade civil na proteção e prevenção contra riscos ambientais, destaca-se que no Brasil, além da previsão constitucional do direito de acesso à informação pública de modo abrangente, na seara ambiental especificamente, a Lei $n^{\circ}$ 10.650/2003, determina que órgãos e entidades integrantes do Sistema Nacional do Meio Ambiente (SISNAMA) fiquem obrigados a permitir o acesso público aos documentos,

\footnotetext{
${ }^{2}$ BRASIL. Lei $\mathbf{n}^{\circ}$ 12.527, de 18 de novembro de 2011. Regula o acesso a informações previsto no inciso XXXIII do art. 5-, no inciso II do $\S 3^{\circ}$ do art. 37 e no $\S 2^{\circ}$ do art. 216 da Constituição Federal; altera a Lei $\mathrm{n}^{\mathrm{o}}$ 8.112, de 11 de dezembro de 1990; revoga a Lei $\mathrm{n}^{\circ} 11.111$, de 5 de maio de 2005, e dispositivos da Lei no 8.159, de 8 de janeiro de 1991. Disponível em:< http://www.planalto.gov.br/>. Acesso em 07 jun. de 2015.

${ }^{3}$ Sistema Nacional do Meio Ambiente - Instituído pela Lei no 6.938/81, o Sistema Nacional do Meio Ambiente (Sisnama) é formado pelos órgãos e entidades da União, do Distrito Federal, dos estados e dos municípios responsáveis pela proteção, melhoria e recuperação da qualidade ambiental no Brasil. Disponível em: < http://www.mma.gov.br/>. Acesso em 14 de jun. de 2015.

${ }^{4}$ Sistema Nacional de Informação sobre Meio Ambiente - O Sistema Nacional de Informação sobre Meio Ambiente (SINIMA) é um dos instrumentos da Política Nacional DOMeio Ambiente, previsto no inciso VII do artigo $9^{\circ}$ da Lei $n^{\circ}$ 6.938/81. O referido sistema é considerado pela Política de Informação do MMA como a plataforma conceitual baseada na integração e compartilhamento de informações entre os diversos sistemas existentes ou a construir no âmbito do SISNAMA (Lei n. 6.938/81), conforme Portaria no 160 de 19 de maio de 2009. Disponível em: < http://www.mma.gov.br/>. Acesso em 14 de jun. de 2015.
} 
processos administrativos e expedientes que tratem de questões ambientais, bem como devem fornecer informações ambientais que estejam sob sua guarda.

Nesse contexto, merece destaque adoção de uma postura proativa governamental, baseada na ideia do governo aberto, a qual consiste em informar o público sobre os seus direitos e promover uma cultura de abertura no seio do governo, através de mecanismos que garantam a liberdade de informação.

As ações do programa de Governo Eletrônico priorizam o uso das tecnologias da informação e comunicação (TIC) para democratizar o acesso à informação, visando ampliar o debate e a participação popular na construção das políticas públicas, como também aprimorar a qualidade dos serviços e informações públicas prestadas.

Conforme demonstram as iniciativas de governo eletrônico e de governo aberto, supramencionadas, as (TIC) têm impulsionado/pressionado essa espécie de reforma na Administração Pública, sendo que a "administração eletrônica" surge como um “instrumento, tanto de uma maior eficiência do serviço público, como de uma maior capacidade de resposta deste às necessidades dos cidadãos" (GONÇALVES, 2003, p. 185).

Assim sendo, a transparência e a divulgação de informações, com ênfase no uso das novas tecnologias, deve contribuir para a participação qualificada e comprometida dos cidadãos, especificamente o direito à informação ambiental:

Destaca-se ainda, como um instrumento norteador de políticas públicas de acesso a informação da água, a Política definida na Lei 9.433 que orientou a elaboração do Plano Nacional de Recursos Hídricos, aprovado em 2006 pelo Conselho Nacional de Recursos Hídricos, por meio da Resolução $\mathrm{n}^{\circ}$ 058, de 30 de janeiro de 2006, compondo-se em um conjunto estratégico de ações e relações interinstitucionais de política, informações e ferramentas de apoio à decisão, implementadas pela União, visando a potencialização e o equacionamento e as soluções regionais ou locais de problemas relativos aos recursos hídricos.

Nesse contexto, o Plano propõe Diretrizes Gerais e uma estratégia: água para todos, promovendo a universalização do acesso à água em áreas rurais para consumo humano e para a produção agrícola e alimentar, visando ao pleno desenvolvimento humano e à segurança alimentar e nutricional de famílias em situação de vulnerabilidade social.

O papel dos Comitês tem papel fundamental, sendo a base da gestão participativa e integrada da água, além de possuírem caráter deliberativo, denominados de Parlamento das Águas, regulamentados de acordo com a Resolução n ${ }^{\circ} 5$ do CNRH, de 10 de abril de $2000^{5}$.

Nesse aspecto, portanto, as ações devem ser direcionadas para que os cidadãos percebam a importância de sua participação, compreendam as questões postas em discussões 
e sintam-se ativamente empoderados para conquistar a posição de atores principais no seio dos Comitês, sempre se levando em conta que o objetivo maior a ser perseguido, de acesso universal à água própria para o consumo humano.

O Pacto Nacional de Gestão pelas Águas, regulamentado pela Resolução ANA n ${ }^{\circ}$ 379/2013, em 21 de março de 2013, elenca os objetivos de promoção efetiva da articulação entre os processos de gestão das águas e de regulação dos seus usos, conduzidos nas esferas nacional e estadual; e fortalecer o modelo brasileiro de governança das águas, integrado, descentralizado e participativo.

Em tempos de sociedade informacional, mesmo com o crescimento de previsões normativas acerca do direito à informação e direito ao acesso à informação pública, ainda é preciso evoluir para que os cidadãos efetivamente participem dos processos democráticos. Outrossim, a informação torna-se peça fundamental para preservação e prevenção do meio ambiente, com a democratização e a politização da informação através da difusão dos meios tecnológicos, principalmente da Internet é possível reduzir a distância do cidadão para acessar a informações ambientais.

\section{PORTAIS BRASILEIROS E A INFORMAÇÃO AMBIENTAL SOBRE A ÁGUA}

Dentro do paradigma tecnológico, cada vez mais se mostra fundamental a ampliação e o melhoramento dos canais de comunicação do governo com a sociedade, visando suprir essa finalidade, foram criadas páginas e portais online com informações, notícias e serviços, surgindo, assim, o Governo Eletrônico $(\text { E-Gov })^{6}$. O desenvolvimento de programas de

\footnotetext{
${ }^{5}$ ANA. O Conselho Nacional de Recursos Hídricos, no uso de suas atribuições, tendo em vista o disposto na Lei ${ }^{\circ}$ 9.433, de 8 de janeiro de 1997, e no Decreto $n^{\circ} 2.612$, de 3 de junho de 1998, e Considerando a necessidade de estabelecer diretrizes para a formação e funcionamento dos Comitês de Bacias Hidrográficas, de forma a implementar o Sistema Nacional de Gerenciamento de Recursos Hídricos, conforme estabelecido pela Lei $\mathrm{n}^{\circ}$ 9.433, de 8 de janeiro de 1997, resolve: Art. $1^{\circ}$ Os Comitês de Bacias Hidrográficas, integrantes do Sistema Nacional de Gerenciamento de Recursos Hídricos, serão instituídos, organizados e terão seu funcionamento em conformidade com disposto nos art. 37 a 40, da Lei $\mathrm{n}^{\circ}$ 9433, de 1997, observados os critérios gerais estabelecidos nesta Resolução. Disponível em: <http://www.cbh.gov.br/>.Acesso em 07 jun. 2015.

${ }^{6}$ Conforme explica Rover "Governo eletrônico é uma infra-estrutura única de comunicação compartilhada por diferentes órgãos públicos a partir da qual a tecnologia da informação e da comunicação é usada de forma
} 
Governo Eletrônico se mostra como uma das diversas iniciativas que visam o aprimoramento e a utilização das TIC para promover a democratização do acesso à informação, ampliar discussões e dinamizar a prestação de serviços públicos, com qualidade e eficiência, mesmo que ainda apresentem informações sistemáticas com pouca interação e transparência.

Nesse contexto a inserção dos Estados na chamada sociedade informacional depende de vários fatores, como econômico e o social, considerando a importância do acesso e da apropriação das Tecnologias da Informação e Comunicação por parte da população, ao que se soma a dimensão política, no contexto de que quanto mais democrático se mostra o Estado, maior será a valorização e mais substanciais serão os investimentos em tecnologias que permitem o acesso do cidadão às informações públicas (SILVA, 2014, p. 244-245).

Levando-se em consideração a delimitação do tema da presente pesquisa, foram identificados sites e portais como referência para demonstração da necessidade de divulgação de informações sobre a situação da água não Brasil. O Sistema Cantareira no Brasil, é um exemplo da ausência de transparência das informações públicas, com relação à crise ambiental em São Paulo. Esse sistema é um sistema de abastecimento de água formado por seis reservatórios localizados ao norte da Região Metropolitana de São Paulo.

Tal o sistema passa por uma crítica situação em decorrência da queda contínua dos níveis de água disponíveis para fins de abastecimento, em razão dos baixos níveis dos reservatórios, desde maio de 2014 a Companhia de Saneamento Básico do Estado de São Paulo (Sabesp) tem oferecido à população água captada abaixo dos níveis normais, o chamado volume morto, que consiste em reserva de água mais profunda do reservatório, localizada abaixo das bombas de captação, utilizada em situações emergenciais. ${ }^{12}$

Desde o agravamento da crise da água no Estado de São Paulo verificou-se a ocorrência de manifestações populares, bem como de iniciativas adotadas por institutos e organizações, no sentido de combater o sigilo de informações e as medidas adotadas para solucionar o problema de escassez.

Uma das iniciativas destacadas, quanto a informações sobre a real situação do sistema Cantareira, foi do Instituto Brasileiro de Defesa do Consumidor, que criou o canal de participação online intitulado "Tô sem água" a fim de apontar e direcionar os problemas apresentados pelos consumidores aos órgãos competentes para solução. Informando ao

intensiva para melhorar a gestão pública e o atendimento ao cidadão. Assim, o seu objetivo é colocar o governo ao alcance de todos, ampliando a transparências das suas ações e incrementando a participação cidadã" (ROVER, 2006, p. 15). 
consumidor, em seu site oficial, que o corte de água sem a declaração por parte do estado enfatizando o racionamento, é ilegal, pelo Código de Defesa do Consumidor e caracteriza a má prestação de serviços, bem como a quebra da continuidade dos serviços públicos essenciais (IDEC, 2015).

No referido site o consumidor internauta pode participar relatando se está faltando água no bairro em que reside, informando a cidade, o bairro, o período e a frequência, ou, ainda, pressionar a Sabesp por mais informações. A campanha "Tô sem Água", desenvolvida através da Internet, se mostrou uma boa ferramenta participativa, com base na Lei de Acesso à Informação, e a empresa forneceu mapas da cidade de São Paulo onde supostamente há falta d'água, representando uma atitude proativa dos consumidores na busca pelo cumprimento do dever de transparência passiva através da mobilização virtual.

Assim, a informação torna-se peça fundamental para a prevenção do meio ambiente, com a democratização e a politização da informação através da difusão dos meios tecnológicos, principalmente da Internet é possível reduzir a distância do cidadão para acessar a informações ambientais. Entretanto, apesar de parte da população ainda não ter computador e muito menos acesso à internet, a propagação da informação através da tecnologia é apenas uma das diversas possibilidades que podem ser utilizadas na busca por soluções da problemática ambiental.

Outros Portais ${ }^{7}$ Brasileiros foram identificados disponibilizando serviços, orientações e informações sobre a água na atualidade: ANA- Agência Nacional de Águas - Conjuntura dos Recursos Hídricos no Brasil, que apresenta um panorama dos recursos hídricos, em escala nacional, e o acompanhamento desse quadro de monitoramento da situação dos recursos hídricos do pondo de vista da quantidade e da qualidade da água, além de avaliar a evolução da estrutura institucional para gestão desses recursos.

A ANA também disponibiliza o programa - Sistema de Informações Hidrológicas, um portal Hidro Web, que oferece um banco de dados sobre bacias, sub-bacias, rios, Estados, Municípios, entidades, estações, séries históricas, disponibilizando mapas, documentos e softwares sobre a situação dos recursos hídricos no Brasil.

No Estado do Rio Grande do Sul, a Secretaria Estadual de Meio Ambiente Departamento de Recursos Hídricos da Secretaria do Meio Ambiente, disponibilizou uma

\footnotetext{
${ }^{7}$ Definição de portal, conforme o Livro Verde da Sociedade da Informação: "site que reúne produtos e serviços de informação de determinada área de interesse e também de interesse geral. Portais de acesso à web normalmente oferecem, por exemplo, serviços gratuitos de correio eletrônico, notícias, chat, informações sobre o tempo, cotação de ações, facilidade para procurar outros sites etc." Sociedade da informação no Brasil : livro verde / organizado por Tadao Takahashi. - Brasília : Ministério da Ciência e Tecnologia, 2000, p. 173.
} 
Cartilha do Usuário da Água, visando prestar informações de cidadania ambiental, quanto a distribuição da água no planeta, legislação, cadastro de uso e usuários das bacias hidrográficas, e acesso ao ICA - informação cidadania e ambiente.

O Instituto Trata Brasil é uma OSCIP - Organização da Sociedade Civil de Interesse Público, formado por empresas com interesse nos avanços do saneamento básico e na proteção dos recursos hídricos do país. Atua desde 2007 trabalhando para que o cidadão seja informado e reivindique a universalização do serviço mais básico, essencial para qualquer nação: o saneamento básico, conscientizando a sociedade para um Brasil mais justo, para que todos tenham acesso à água tratada, coleta e tratamento dos esgotos (INSTITUTO TRATA BRASIL, 2015)

O Portal Brasil, Programa Nacional de Vigilância da Qualidade da Água para Consumo Humano - VIGIAGUA- estruturado a partir dos princípios do Sistema Único de Saúde (SUS), desempenha um papel importante para garantir a qualidade e segurança da água para consumo humano no Brasil. Reúne dicas para evitar o desperdício de água, para a utilização dos recursos hídricos com sustentabilidade, informando que a água utilizada para consumo humano é um bem essencial que garante saúde e qualidade de vida à população, quando distribuída em quantidade suficiente e com qualidade que atenda ao padrão de potabilidade estabelecido na legislação vigente (PORTAL BRASIL, 2015).

Portal da Embrapa - Empresa Brasileira de Pesquisa Agropecuária do Ministério da Agricultura, Pecuária e Abastecimento- Água na Agricultura - Desafio do uso da água na agricultura brasileira, traz informações relevantes quanto ao conhecimento científico gerado nas últimas décadas comprova ser possível utilizar água na agricultura com racionalidade e sem desperdício. Diante da crise hídrica em regiões importantes do Brasil, é fundamental que a sociedade tenha acesso a este conhecimento. Aqui você encontrará soluções tecnológicas desenvolvidas ou adaptadas para diferentes biomas, que mostram como usar a água na produção vegetal e na criação animal (PORTAL EMBRAPA, 2015).

Portal do Ministério do Meio Ambiente- Programa- Programa Água Doce - O Programa Água Doce (PAD) é uma ação do Governo Federal coordenada pelo Ministério do Meio Ambiente, por meio da Secretaria de Recursos Hídricos e Ambiente Urbano, em parceria com instituições federais, estaduais, municipais e sociedade civil. Visa o estabelecimento de uma política pública permanente de acesso à água de boa qualidade para o consumo humano, promovendo e disciplinando a implantação, a recuperação e a gestão de sistemas de dessalinização ambiental e socialmente sustentáveis para atender, prioritariamente, as populações de baixa renda em comunidades difusas do semi-árido 
(MINISTÉRIO DO MEIO AMBINTE, 2015).

Os Portais analisados representam novos paradigmas, um novo processo de interação social, organização e formação de uma cidadania participativa, a qual tem se desenvolvido e se intensificado com o apoio das tecnologias de informação. Neste contexto, a sociedade informacional permite que uma das armas mais importantes de poder, a informação, seja rapidamente difundida, aliando-se aos modernos meios de comunicação, como a internet. As informações identificadas podem ser relacionadas como sistemáticas, e os mecanismos de participação para os cidadãos, que se restringem a coleta de reclamações, sem um mecanismo efetivo de comprovação quanto ao atendimento e satisfação das questões suscitadas.

Observando-se ainda que esse novo paradigma ainda está muito distante de um plano ideal, com a difusão de informações sobre nossas fontes de recursos hídricos, tanto em qualidade como quantidade, seja efetivada de forma mais satisfativa, incluindo os cidadãos em um processo participativo, de orientação e busca por soluções comuns. Não podemos deixar de mencionar a exclusão tecnológica que ainda se reflete em nosso país, com acessos insuficientes para possibilitar uma política pública de qualidade e transparência.

\section{CONCLUSÃO}

O presente trabalho buscou evidenciar a utilização das tecnológicas de informação, na sociedade informacional, em um processo de transformação social, inserindo um contexto de informações sobre os usos da água em portais do Governo Brasileiro e de Organizações não governamentais, com o intuito de esclarecer, educar e alertar a população, quanto aos riscos inerentes a utilização da água nos seus aspectos de qualidade e quantidade.

O reconhecimento do direito à informação, no Brasil, passou por um processo lento e gradativo de evolução. Apesar de ter sido elencado como fundamental no artigo no artigo $5^{\circ}$, XXXIII da Constituição Federal de 1988, somente foi regulamentado pela Lei 12.527, promulgada em 18 de novembro de 2011, observando-se à necessidade de implementação da cultura de acesso prevista na nova legislação, baseada na publicidade e na transparência como regra, em detrimento do sigilo, fazendo com que o Poder Público se aproprie e adote ferramentas e procedimentos para a efetivação do acesso à informação na Internet, além das mídias tradicionais.

O direito à água se vincula estritamente ao direito à vida, e, portanto, assume a condição de direito humano, de uma nova cultura da água pautado em uma gestão equitativa capaz de reconhecer o caráter intergeracional atribuído aos bens ambientais, solidária e 
sustentável deve ser introduzida, para que se possam ter um novo olhar, para além das crises vivenciadas na atualidade.

Desse modo, os portais representam uma importante fonte de informações, para os cidadãos sejam capazes de formular uma leitura adequada da realidade e influenciar positivamente nos processos decisórios em diferentes esferas da sociedade. A informação, por permitir o monitoramento e a participação, é ferramenta indispensável de controle democrático sobre instituições estatais, razão pela qual o direito à informação está intimamente ligado ao conceito de democracia participativa e respeito aos direitos fundamentais.

Pode-se dizer, assim, que as TIC não são propulsoras unilaterais da democracia participativa no meio digital, mas sim importantes ferramentas para intervir em uma complexa reestruturação do Estado e da sociedade, envolvendo não só a apropriação das novas tecnologias, mas também a convergência de iniciativas para a consolidação do viés democrático, sobretudo, através da transparência e da garantia do direito à informação.

Deve-se dar ênfase especial à transformação da informação existente em formas mais úteis para a tomada de decisões e em orientá-la para diferentes grupos de usuários. Devem- se estabelecer ou fortalecer mecanismos para converter as avaliações científicas e socioeconômicas em informação adequada para o planejamento e a informação pública.

$\mathrm{Na}$ busca de um novo paradigma, de que as políticas sejam adequadamente implantadas e mantidas, com a implementação de uma proposta de desenvolvimento sustentável, mediante um sistema nacional que tenha como norte o entendimento de que a água é um recurso natural indispensável à vida humana, somente assim, se possibilitará a proteção desse recurso em quantidade e qualidade para as presentes e futuras gerações indistintamente. Desta forma, verifica-se a emergência da efetivação da água como direito fundamental, bem como do direito de acesso as informações referentes à governança e gestão dos recursos hídricos, como dever premente do poder público em benefício da coletividade, demonstrando-se a necessidade de abertura de novos canais de comunicação e de participação entre o cidadão e o gestor público, no tratamento da água como direito fundamental.

\section{REFERËNCIAS}

AGNE TYBUSCH, Francielle Benini. Biodiversidade, Tecnologia e Sociedade: O Direito à informação ambiental sustentável como possibilidade emancipatória na proteção dos conhecimentos tradicionais. Dissertação - Universidade Federal de Santa Maria, 2016. 
ANA. Pacto Nacional de Gestão pelas Águas Instrumentos de Gestão das

Águas. Disponível em: < http://www2.ana.gov.br/ >. Acesso em: 07 jun. 2015.

2015 .

. Sistema Cantareira. Disponível em: <www2.ana.gov.b>. Acesso em: 07 jun. de

Conjuntura dos Recursos Hídricos no Brasil. Disponível em:

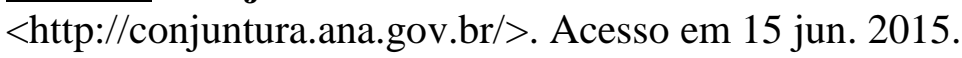

Hidro Web. Sistema de Informações Hidrológicas. Disponível em:<

http://hidroweb.ana.gov.br/>. Acesso em: 20 jun. 2015.

BRASIL. Artigo 19. O direito do público a estar informado. Princípios sobre a legislação de liberdade de informação. Artigo 19: Londres, 1999, p. 6. Disponível em:<http://www.article19.org >. Acesso em: 07 jun. 2015.

. Constituição Federal. Brasília: Senado Federal, 1988.

Disponível em:<http://www.planalto.gov.br/>. Acesso em: 02 jun. 2015.

Governo Eletrônico. Disponível em: <

http://www.governoeletronico.gov.br>. Acesso em: 07 jun. de 2015.

Lei $\mathbf{n}^{0}$ 12.527, de 18 de novembro de 2011.

Disponível em: <http://www.planalto.gov.br/>. Acesso em 07 jun. de 2015.

Lei $\mathbf{n}^{\mathbf{0} 9.433}$, de 8 de janeiro de 1997. Institui a Política Nacional de Recursos Hídricos, cria o Sistema Nacional de Gerenciamento de Recursos Hídricos. Disponível em:< http://www.planalto.gov.br/>. Acesso em: 19 jun.2015.

.Lei no 10.650, de 16 de abril de 2003. Disponível em:

<http://www.planalto.gov.br/>. Acesso em 07 jun. 2015.

MINISTÉRIO MEIO AMBIENTE. Programa Água Doce. Disponível em: < http://www.mma.gov.br/agua/agua-doce>. Acesso em 15 jun. 2015.

PORTAL BRASIL. Programa Nacional de Vigilância da Qualidade da Água para Consumo Humano (Vigiagua) Disponível em: < portalsaude.saude.gov.b/>. Acesso em 15 jun. 2015.

PORTAL - EMBRAPA - Empresa Brasileira de Pesquisa Agropecuária do Ministério da Agricultura e Abastecimento. Água na Agricultura. Disponível em: < www.embrapa.br/agua-na-agricultura>. Acesso em 15 de jun. 2015. 
Sistema Nacional Do Meio Ambiente. Instituído pela Lei no 6.938/81.

Disponível em: < http://www.mma.gov.br/>. Acesso em 14 de jun. de 2015.

BOFF, Leonardo. A grande transformação: na economia, na política e na ecologia.

Petrópolis, RJ: Vozes, 2014.

CASTELLS, Manuel. A sociedade em rede - a era da informação: economia, sociedade e cultura. 5. ed. Traduzido por Klauss Brandini Gerhardt e Foneide Vanancio Majer. São Paulo: Paz e Terra, 1999.

DIREITOS EMERGENTES NA SOCIEDADE GLOBAL- Anuário do Programa de PósGraduação em Direito da UFSM. Organizadores: Jerônimo Siqueira Tybusch; Luiz Ernani Bonesso de Araujo; Rosane Leal da Silva. Ijuí. 2013

ESTADO DO RIO GRANDE DO SUL. Secretaria Estadual de Meio Ambiente Departamento de Recursos Hídricos da Secretaria do Meio Ambiente. Cartilha do Usuário da Água. Disponível em: < http://www.sema.rs.gov.br/>. Acesso em 15 jun. 2015.

GIDDENS, Anthony. As consequências da modernidade. Traduzido por Raul Fiker. São Paulo: Editora UNESP, 1991.

GONÇALVES, Maria Eduarda. Direito da informação: novos direitos e formas de regulação na sociedade da informação. Coimbra: Almedina, 2003.

IDEC. Instituto Brasileiro de Defesa do Consumidor. Especial Tô Sem Água. Disponível em: <http://www.idec.org.br/especial/to-sem-agua>. Acesso em: 07 jun.. 2015.

INSTITUTO TRATA BRASIL. Organização da Sociedade Civil de Interesse Público. Disponível em: < http://www.tratabrasil.org.br/>. Acesso em 15 jun. 2015.

LUÑO, Antonio Enrique Pérez. Los Derechos Humanos en la Sociedad Tecnológica. 1 ed., Editora Univeritas, S.A., 2012.

MACHADO, Paulo Affonso Leme. Direito à Informação e Meio Ambiente. São Paulo: Editora Malheiros, 2006.

SABESP - Companhia de Saneamento Básico do Estado de São Paulo. Disponível em: $<$ http://www2.sabesp.com.br/>.Acesso em 15 jun. 2015.

SILVA, Rosane Leal da. A Contribuição dos Sites e Portais do Poder Executivo Federal para o Incremento do Controle Social. Mídias e Direitos da Sociedade em Rede. Organizadores: Rafael Santos de Oliveira e Marília de Nardin Budó. Ijuí. Unijuí, 2014. p. 244-245. 